\title{
THE 1991 AEGON MAN-COMPUTER TOURNAMENT
}

\author{
Cock de Gorter
}

The 1991 AEGON man-computer tournament will be held on eight days spanning May 22 and May 29, 1991 inclusive. On all competition days playing times will be from 7.30 to 11.30 p.m. local time. The location of the tournament will be the main office of AEGON, Mariahoeveplein 50, The Hague, The Netherlands.

This tournament is the $6^{\text {th }}$ annual venture in its series. It is sponsored by the AEGON insurance company, and is now the $8^{\text {th }}$ tournament, organized by Cock de Gorter in which man and computer meet on equal basis. The year 1990 saw a thrilling performance, in which Hitech, by Carnegie-Mellon University, Piket, an IGM, and Blokhuis, a rank outsider, tied at 5-1. It was also honoured by IGM Bronstein, a former World Champion Challenger. All those four aces will re-enter in 1991, with many a strong contender to dispute them. (See ICCA Journal, Vol. 13, No. 2, pp. 99-113 for reports on the 1990 AEGON man-computer tournament.)

The complete list of participants reads:

\section{Humans}

IGM Bronstein, IGM Sosonko, IGM Van der Wiel, IGM Piket, IGM Christiansen, FM Wind, NM V.d. Berg, Blokhuis, Jongsma, Bakker, Loewenthal, Kieboom, Krabbé, Pam, Voortmeijer, V.d. Laan.

\section{Computers}

Hitech, Mephisto (world champion micro), Mephisto Lyon 68030, Mephisto Polgar, Elite 68040, Elite 68030, Elite 68020, Novag Diabolo, Novag Scorpio, Novag Super Expert, Rexchess IBM 80486, M Chess IBM 80486, Quest IBM 80486, Chessmachine Risc, The King Risc, Echecs IBM 80486 (invited), Sargon IV IBM 80486.

Prof. dr. Hans Berliner, the human force behind Hitech, will also come over to watch his darling Hitech play, comment on its performance and possibly spark it.

For more information, please contact

Cock de Gorter

Obrechtstraat 402

2517 VJ The Hague, The Netherlands

\begin{abstract}
AN APOLOGY
The printers greatly regret that, by their intermediary, compounded by a fault of their own, subscribers in North America have suffered a grave delay in delivery for the third time running, in spite of the earnest undertaking given in the previous issue (Vol. 13, No, 4, p. 207).

The error is regretted and readers are entitled to as handsome an apology as the printer can provide. Meanwhile, all efforts have been made so as to prevent a further incidence of this postponed delivery. The printers wish to point out that any delay our subscribers may have suffered is in no way due to Editorial activities, since the Editors, we testify, have prepared copy for the printers well in time to ensure undelayed delivery.
\end{abstract}

Th. van Spijk, Venlo, The Netherlands 